\title{
LA CRUZ DE LAS PENAS DE SAN VICENTE
}

\author{
POR GERARDo GarCía LEÓN
}

La Semana Santa de Sevilla cuenta entre sus innumerables tesoros artísticos con una pieza extraordinaria y afamada, cuya riqueza y singularidad la sitúan en un destacado lugar dentro de la historia del arte andaluz. La cruz de carey y plata que soporta la devota imagen de N.P. Jesús de las Penas, de la iglesia de San Vicente Mártir, es un riquísimo atributo con el que sus piadosos hermanos le adornan cada año, en su recorrido procesional por las calles de Sevilla (Lám. 1-2).

Esta cruz pertenece a la cofradía de nazarenos de Nuestro Padre Jesús de las Penas y Nueswa Señora de los Dolores desde el año 1967. En dicho año, tras recabar diversos informes técnicos, fue legalmente adquirida a la hermandad de Nuestro Padre Jesús Nazareno, Santa Cruz en Jerusalén y Nuestra Señora de las Misericordias, establecida en la iglesia de San Juan Bautista de Écija. En este artículo abordamos los orígenes de la hermandad ecijana, el momento en que se ejecutó la cruz, y las circunstancias que rodearon su definitivo traslado a Sevilla y posterior restauración. En esencia, el contenido de nuestro trabajo responde a una comunicación que, sobre este tema, presentamos en el II Congreso de Historia "Écija en el siglo XVIII", celebrado en Écija en 1988, cuyas actas permanecen inéditas.

La hermandad de N.P. Jesús Nazareno y Santa Cruz en Jerusalén es una de las cofradías ecijanas cuyos inicios se remontan al siglo XVI. El decreto de aprobación de su libro de reglas está fechado en Sevilla el día 6 de marzo de 1582, conociéndose que el fundador de la congregación fue un personaje llamado Juan de Santa María ' . Por estas fechas la cofradía únicamente rendía culto a la Santa Cruz de Jerusalén. Sin embargo, es difícil precisar en qué momento

1. GARCÍA LEÓN, G.: "La hermandad de Nuestro Padre Jesús Nazareno y Santa Cruz en Jenusalén de Écija", en Actas del Congreso Internacional Cristóbal de Santa Catalina y las cofradías de Jesús Nazareno, Tomo II, Córdoba, 1991, pp. 611-622. 
histórico y bajo qué circunstancias sociales pudo originarse esta asociación piadosa; en cuanto a su primitiva sede las reglas no mencionan de manera explícita el lugar donde radicaba oficialmente la hermandad.

A partir de 1592 encontramos las primeras noticias que confirman su establecimiento en la parroquia de San Juan Bautista; en 1602 la hermandad pasó a ocupar la antigua capilla sacramental del templo, compartiéndola con la hermandad de las Ánimas Benditas del Purgatorio. A comienzos del siglo XVII la devoción se centró en la figura de Jesús Nazareno, ampliándose posteriormente a la Virgen Dolorosa, San Juan Evangelista y la Verónica. A lo largo de la historia, la hermandad amplió su capilla, costeó retablos y adornos para sus veneradas imágenes, e incluso sobrevivió al derribo del templo parroquial que le dio acogida, ocurrido a fines del siglo XVIII.

La extracción social de los cofrades de Jesús Nazareno era diversa, encontrándose entre ellos, desde menestrales y labradores, hasta destacados miembros de la nobleza terrateniente local. Durante el siglo XVII el cabildo que controlaba el gobierno de la hermandad estaba formado generalmente por escribanos públicos, procuradores, hidalgos, caballeros jurados del Ayuntamiento y plateros. Pero ya desde fines de esta centuria, y a lo largo de toda la siguiente, se observa la presencia de numerosos e importantes miembros de la nobleza ecijana, como los marqueses de las Cuevas del Becerro, Alcántara del Cuervo, Peñaflor y Quintana de las Torres. La hermandad también podía acoger en su seno a mujeres, pudiendo ser éstas casadas o doncellas, y también a religiosas de los conventos. Se conservan en el archivo de la hermandad libros registros de hermanas desde 1661, y entre los conventos cuyas monjas eran hermanas de Jesús Nazareno, en el siglo XVIII, se encontraba el monasterio de Santa Inés del Valle y los conventos de Santa Florentina, Espíritu Santo y Ntra. Sra. de los Remedios ${ }^{2}$.

Aparte de las diversas fiestas y solemnidades que la hermandad celebraba anualmente -fiesta de la invención de la Santa Cruz, Cuaresma, fiesta de San Juan Evangelista, etc.- gozaban de gran esplendor las funciones de Semana Santa. El desfile procesional se efectuaba en la madrugada del Viernes Santo, y se componía de cuatro pasos o andas, sobre los que se portaba a Nuestro Padre Jesús Nazareno, Nuestra Señora de los Dolores, San Juan Evangelista y la Verónica con el paño ${ }^{3}$.

Las fuentes de ingresos de la hermandad se nutrían fundamentalmente de los réditos de algunos censos ${ }^{4}$, y sobre todo, de limosnas obtenidas en las funciones

2. Archivo de la Hermandad de Jesús Nazareno, libro registro de hermanas (1696-1782) S/F.

3. Una relación curiosa de los gastos ocasionados en los cultos celebrados por esta hermandad, el año 1770, puede encontrarse en Archivo Municipal de Écija, leg. 2.501.

4. Según el Catastro del Marqués de Ensenada, de 1755, la hermandad percibía los siguientes ingresos: 
religiosas y en varios puestos o demandas que se instalaban en lugares populosos y concurridos de la ciudad, como eran el camino del Valle, la portería del convento del Espíritu Santo, y la esquina de la calle Platería ${ }^{5}$. En este sentido, a lo largo del siglo XVIII, era habitual que la diferencia existente entre gastos e ingressos fuese ofrecida cada año a la hermandad por parte del hermano mayor, una de cuyas funciones era administrar los ingresos y rendir cuentas anuales a la congregación. Como ejemplo de las limosnas y donaciones que la hermandad solía recibir, detallamos a continuación sólo algunos de los regalos más significativos ofrecidos en 1715, con motivo de la renovación de la capilla: Marcos Felipe Dorado, capellán de honor de su majestad, donó el retablo mayor de la capilla y una araña dorada para su iluminación; Marcos Zaldúa, presbítero, dio otras dos arañas de plata; y ciertas señoras regalaron dos faroles y seis candeleros de plata para el altar, así como una efigie nueva de la Verónica ${ }^{6}$.

Era habitual que tanto el hermano mayor, como el resto de los componentes del cabildo, pertenecieran a los estamentos privilegiados de la ciudad. Durante buena parte del siglo XVII, pero principalmente a lo largo de la siguiente centuria, encontramos ocupando los cargos de hermano mayor o diputado, al marqués de las Cuevas del Becerro, al marqués de Quintana de las Torres, o al marqués de Peñaflor ${ }^{7}$. Sin embargo, uno de los protagonistas más destacados en la historia de la hermandad de Jesús Nazareno fue el marqués de Alcántara del Cuervo. Desde los primeros instantes documentados su nombre aparece con frecuencia en los cabildos ostentando el cargo de hermano mayor. Debió ser uno de los personajes más influyentes de su época, y según el informe reservado de la visita arzobispal a Écija, celebrada el día 15 de octubre de 1704, sus rentas anuales ascendían a 8.000 ducados, lo que le situaba entre las primeras fortunas de la ciudad ${ }^{8}$. En el testamento otorgado por el marqués de Alcántara del Cuervo en 1725, se detallaban las donaciones de alhajas que había hecho en vida a la hermandad de Jesús Nazareno, y las limosnas y mandas piadosas que, tras su muerte, dejaba ordenadas. También encargaba expresamente a sus albaceas que

- Tributo de 12 reales de vellón de réditos anuales, valor de una arroba de aceite que paga don Antonio de Landa, como marido de doña María Josefa de León, sobre olivares Pago Fuente de los Cristianos.

- Tributo de 6 reales de vellón de réditos anuales, valor de media arroba de aceite que paga Sebastián Alfonso, sobre olivares en el Pago del Garabato.

(Vid. A.M.E., libro 1.128, fol. 4.887v-4.888).

5. A.H.J.N., libro de cabildos y cuentas, S/F. En la calle Platería se exhibía una reproducción de Jesús Nazareno durante la demanda a la que se colocaba incluso potencias de plata.

6. Ibidem, cuentas de 1715 .

7. Ibidem.

8. Archivo Palacio Arzobispal de Sevilla, leg. 11 (Visitas). 
devolvieran al nuevo hermano mayor de la hermandad un arca de madera donde se custodiaban los documentos que formaban el archivo de la congregación ${ }^{9}$.

En 1734, Manuel de Villavicencio Castrillo y Moscoso, nuevo marqués de Alcántara del Cuervo ${ }^{10}$, como hermano mayor de la hermandad de Nuestro Padre Jesús Nazareno, fue el encargado de firmar una escritura de obligación mediante la que se contrataba la ejecución de una cruz de carey y plata para la imagen del titular. El documento fue suscrito en Écija el día 30 de mayo de 1734, por Juan Francisco de Pareja, maestro ebanista, vecino de Andújar, y residente para este fin en Écija, ante el escribano público Francisco Manuel Peláez ". Por él se obligaba a ejecutar una cruz de carey, embutida de plata, para la imagen de Jesús Nazareno venerada en la parroquia de San Juan Bautista, en base a las condiciones siguientes:

- La hermandad se obliga a facilitar una dependencia donde el artífice pueda instalar su taller y desarrollar su trabajo.

- Serán por cuenta de la hermandad toda la plata y el carey que se necesiten para hacer la cruz.

- El salario para el otorgante será de 14 reales de vellón diarios.

- Si fuera preciso se buscará un oficial ayudante, al que se abonarán 7,17 reales de vellón al día.

- El otorgante se obliga a ejecutar la cruz desde primeros de junio de 1734 y a entregarla perfectamente terminada por las mismas fechas de 1735 .

- El artífice mostrará varios diseños de la cruz, para que la hermandad elija el que pareciere más conveniente.

Una vez firmada la escritura debieron presentarse los dibujos de que se habla en las condiciones, de los cuales no hemos hallado el menor rastro. Tampoco tenemos noticias sobre las circunstancias que rodearon la ejecución de la cruz; si fue precisa la colaboración del oficial; si el trabajo de la plata fue encargado a un platero, etc. Pero si hacemos caso a las indicaciones del contrato, la cruz debió estar finalizada en junio de 1735. El archivo de la hermandad carece de documentación para el período 1723-1759, lo cual hace prácticamente imposible hallar información sobre el coste total de la cruz. Dicho coste tuvo que ascender a una suma verdaderamente considerable si tenemos en cuenta el plazo de ejecución -un año- y el altísimo salario ofrecido al maestro ebanista -14 reales de vellón-. Como ejemplo ilustrativo diremos que, entre 1708 y 1747, el salario de

9. GARCÍA LEÓN, G.: La orfebrería en Écija, tesis doctoral inédita.

10. En 1722 se concedió a don Manuel de Villavicencio, hijo del marqués de Alcántara del Cuervo, el privilegio de portar una de las horquillas del paso de Jesús Nazareno. A.H.J.N., libro de cabildos y cuentas, $\mathrm{S} / \mathrm{F}$.

11. Archivo de Protocolos de Écija, leg. 2.771, fol. 467-468v. Véase documento anexo. 
los mejores ebanistas y carpinteros de lo primo de Écija no superaba los 9 reales al día, oscilando el sueldo del oficial entre 4 y 6 reales diarios ${ }^{12}$.

No debemos olvidar que las mejores alhajas y ornamentos de la hermandad procedían de donaciones y limosnas, y que precisamente es el marqués de Alcántara del Cuervo quien, como hermano mayor, suscribe el encargo. Carecemos de pruebas para afirmar que la cruz fuese un regalo del mismo, por lo que dejamos para futuras investigaciones la resolución de esta enigma.

Después de 1759, aunque existen actas de cabildos y cuentas, no se conservan inventarios de bienes que pudieran atestiguar la presencia de la cruz en poder de la hermandad. El primer documento que hemos localizado, donde aparece mencionada, es un inventario efectuado el día 7 de febrero de 1783. En este día, por orden del visitador arzobispal, se llevó a cabo un inventario formal de todos los objetos y enseres que existían en la parroquia de San Juan Bautista, incluida la capilla de Jesús Nazareno, y en él se cita "una cruz que tiene Nuestro Padre Jesús en los onbros de carey y enbutidos de plata" ${ }^{13}$. De ello deducimos que la cruz era utilizada tanto en los desfiles procesionales, como durante el tiempo que la imagen permanecía en su camarín. Para la procesión anual, la cruz era montada sobre una estructura de hierro oculta bajo la túnica del Nazareno, y era fijada a la oreja izquierda de la imagen mediante un perno metálico, que aún se conserva en la parroquia de San Juan Bautista (Lám. 3, 4 y 5).

Estudiada toda la documentación generada por la hermandad durante el siglo $\mathrm{XX}$-al menos la que hemos podido consultar- no hallamos noticias sobre la cruz, por lo que damos por hecho que la misma continuó en su poder sin ninguna incidencia. En 1958 la hermandad amplió la longitud de la canastilla del paso del Nazareno ${ }^{14}$, este hecho provocaba cierta desproporción entre el tamaño de la cruz de carey que portaba la imagen, y el nuevo paso que se había construido. Además, en dicho año se restauró la imagen cambiando su posición hierática tradicional por una actitud de avance, con el torso ligeramente inclinado hacia adelante. Por esto, la antigua cruz quedó en desuso y fue sustituida en 1960 por una cruz arbórea de mayor longitud ${ }^{15}$.

En 1965 se entablaron conversaciones con la hermandad de Nuestro Padre Jesús de las Penas, sita en la parroquia de San Vicente, de Sevilla, encaminadas a la venta de la primitiva cruz. Dichas conversaciones fructificaron y, solicitada la

12. FERNÁNDEZ MARTÍN, M. Mercedes: El gremio de carpinteros de Écija durante el siglo $X V I I I$. Artistas y obras, tesis doctoral inédita. Por las mismas fechas un maestro platero ganaba 4 reales al día, y el oficial, 3 reales. GARCíA LEÓN, G.: El gremio de plateros de Écija. Aspectos documentales. Tesis de licenciatura inédita, pág. 61.

13. GARCÍA LEÓN, G.: La orfebrería de Écija, ob. cit.

14. A.H.J.N., libro de cabildos y cuentas, S/F, cuentas de 1958.

15. Ibidem. 
correspondiente autorización eclesiástica, el día 22 de abril de 1967 el vicario general del arzobispado, por orden del Cardenal Bueno Monreal, firmaba el decreto que permitía la enajenación de esta obra de arte. Por estas fechas había sido suscrito el contrato de venta entre la hermandad de Jesús Nazareno, de Écija, y José Martínez Luna, vecino de Sevilla, que actuaba en nombre de varios hermanos de la Hermandad de las Penas, a la cual pensaban donarla ${ }^{16}$.

Al pasar a poder de la hermandad de las Penas, la cruz presentaba varios orificios practicados desde antiguo para ser colocada en la imagen ecijana; además había perdido carey y plata en diferentes zonas. Por ello fue restaurada en 1968 bajo la dirección de Juan Carrero Rodríguez, corriendo a cargo "en la parte de carpintería y ensamblaje de las piezas de carey, de José Lunar Martínez, mientras que la plata se reprodujo en los talleres de Roncero, de Córdoba, y ajustadas a la cruz por el tallista Antonio Vega Sánchez. Así mismo, y una vez efectuada la restauración, se amplió la cruz con unos casquetes proyectados también por el que dirigí la obra, y que ejecutó en plata de ley el orfebre Jesús Domínguez Vázquez; las plantas de carey fueron suministradas y realizadas por el especialista Francisco Tejada" ${ }^{17}$.

Según informaciones facilitadas por el propio señor Carrero Rodríguez, los casquetes añadidos fueron inspirados a partir de los que posee una cruz, también de carey y plata, que preside el misterio de la Quinta Angustia, uno de los pasos que integran la cofradía ecijana de Nuestra Señora de la Soledad y Santo Entierro de Nuestro Señor Jesucristo, sita en la iglesia del exconvento del Carmen Calzado.

Hoy en día, completamente restaurada y notablemente realzada, esta magnífica cruz puede ser admirada en la sede de la hermandad propietaria, donde la hemos estudiado. Cada año, la noche del Lunes Santo procesiona las calles de Sevilla, a hombros de la devota imagen de Jesús de las Penas.

Tras la restauración llevada a cabo, la cruz mide con los nuevos remates 3,06 x $1,91 \mathrm{~m}$. Además de los remates, se añadió un trozo de $9 \mathrm{~cm}$. a la parte inferior del vástago mayor o "patíbulum", para lo que hubo que reproducir minuciosamente la decoración utilizada en la obra, y emplear materiales preciosos de semejante calidad. Según pudo observarse durante la restauración, la cruz está construida con madera ensamblada, madera cuya naturaleza no fue determinada. De sección rectangular, -mide $12,5 \times 6 \mathrm{~cm}-$, la superficie exterior está cubierta completamente de grandes conchas de carey perfectamente pulimentado, sobre

16. Ibidem. Existe un pequeño folleto publicado en 1967 donde se recogen opiniones favorables a la adquisición de la cruz formuladas por José Sebastián Bandarán, presbítero, Alfonso Grosso, pintor, y Cayetano González, orfebre.

17. CARRERO RODRÍGUEZ, J.: Anales de las cofradias sevillanas, Sevilla, 1984, pág. 151. 
las que se han embutido, mediante un proceso hasta hoy desconocido, una serie de pequeñas piezas de plata, trabajadas a buril, que representan temas vegetales y geométricos. Repartidos por toda la superficie de la cruz, estos motivos se alternan y combinan formando rombos, cruces y rosetas octogonales. Esta decoración abigarrada se articula de tal forma que siempre ofrece el mismo esquema desde cualquier punto que observemos la cruz (Lám. 6).

El diseño original, la riqueza de los materiales, y la calidad con que se ejecutaron las incrustaciones, hacen de esta pieza una obra de primera categoría ${ }^{18}$. Aunque ha sido vinculada con obras de procedencia americana ${ }^{19}$, nos inclinamos a pensar que la cruz difiere notablemente de otras cuyo origen colonial sí está demostrado ${ }^{20}$, independientemente de la evidencia documental. Aunque hemos indagado sobre la personalidad del artífice Juan Francisco de Pareja, desconocemos por ahora cualquier noticia sobre sus posibles obras en la ciudad de Andújar. Únicamente podemos afirmar que debió ser un artista importante, muy cotizado en su época, a juzgar por el excesivo salario y las condiciones ventajosas estipuladas en el contrato; y que la cruz que labró para la hermandad de Jesús Nazareno es una obra notabilísima que no tiene parangón con ningún otro ejemplo similar conocido. Tanto en diseño, como en técnica de ejecución, esta cruz se singulariza del resto de cruces procesionales coetáneas existentes en Andalucía. Aunque es muy común la presencia de cruces de carey, la mayoría de ellas se decoran con aplicaciones de plata sobrepuestas, no embutidas, como sucede en la obra que nos ocupa. Cuando aparecen incrustaciones o embutidos, suele tratarse de piezas de nácar o de marfil, y en muy pocos casos, de plata.

La extraordinaria riqueza y suntuosidad de esta cruz quedaba ampliamente justificada para la hermandad ecijana por ser precisamente la Santa Cruz de Jerusalén el objeto supremo de su adoración; al revestir a su imagen titular con este simbólico y precioso atributo, se potenciaba el culto a Jesús Nazareno y se mantenía la fidelidad a la primitiva devoción originada en 1582.

Finalmente, a la hora de comprender la significación que la cruz de la hermandad de N.P. Jesús Nazareno tuvo para la Semana Santa de Écija, no podemos olvidar la presencia de otras dos singulares piezas, también de carey y plata. Nos referimos a la cruz del misterio de la Quinta Angustia, y a la importantísima urna-sepulcro de Cristo, ambos propiedad de la hermandad de Nuestra Señora de la Soledad y Santo Entierro de Nuestro Señor Jesucristo, obras ejecutadas durante el primer tercio del siglo XVIII.

18. SANZ SERRANO, M." Jesús: "Las artes omamentales en las cofradías de la Semana Santa sevillana", dentro de Las cofradías de Sevilla. Historia, antropología, arte, Sevilla, 1985, pág. 160.

19. CARRERO RODRÍGUEZ, J.: Ob. cit., pág. 151.

20. Una interesante colección de cruces procesionales puede encontrarse en la obra: Gloria Nazarenorum. Origenes de nuestra Semana Santa, Sevilla, 1987. 
Archivo de Protocolos de Écija, leg. 2.771, fol. 467-468v.

"En la ziudad de Ezixa en treinta días del mes de Mayo de mill setecientos y treinta y quatro años, ante mí el escrivano público y testigos ynfrascriptos parezió Don Juan Francisco de Parexa, vecino de la ziudad de Andúxar y rezidente en ésta, y otorgó que se obligaba y obligó de hazer y executar por sí una cruz de carey embutida en plata para Nuestro Padre Jesús, sita en la Yglesia Parroquial de Señor San Juan Baptista de esta dicha ciudad, a satisfazión de la Hermandad, rematada y acavada en todos sus perfiles, dándosele por dicha Hermandad y su Hermano mayor quarto en que asista en esta Ciudad para executar dicha obra, y a un ofizial si lo nezesitare, pagándole a el otorgante en cada un día de los que trabaxare catorze reales de vellón y a el ofizial, siete reales y medio de vellón, y asímismo los días que a el otorgante echare en venir a esta Ciudad, y bolver a la de Andúxar; cuias pagas de hornales se an de satisfazer por dicha Hermandad por semanas, conforme fuere trabaxando, y dándosele por dicha Hermandad sólo el carey y plata que nezesitare para executar dicha cruz, sin otra cossa alguna, que lo demás que sea concerniente para executarla a de ser de su quenta y cargo del otorgante, quien assí mismo se obliga a empezar a executar dicha cruz en todo el mes de junio próximo que bendrá de este presente año de la fecha, y a darla perfectamente acavada a satisfazión de la dicha Hermandad con todos sus perfiles y demás que nezesite, para el día próximo a el de Junio del año que viene de mill setezientos y treinta y sinco, para lo qual a de traer dibuxos para que por dicha Hermandad y su Hermano mayor se elixa el que pareziere más combeniente para executar dicha cruz, y por el que assí se elixere la a de executar sin embarazo alguno. Todo lo qual cumpliéndose por la dicha Hermandad con todo lo que ba expressado, el otorgante se obligava y obligó a hazer y executar la dicha cruz en la conformidad que ba expressado, y a traer dibuxos sufizientes para que por dicha Hermandad se haga eleczión del que pareziere más combeniente. Por todo lo qual, cada cosa o parte de ello, se le pueda apremiar a su efectibo cumplimiento con esta escriptura, y sin que sea nezesario otro auto, prueba, sitazión alguna, aunque de derecho se requiera.

Y estando presente a lo expressado en esta escriptura Don Manuel de Villavizenzio Castrillo y Moscoso, Marqués de Alcántara del Cuerbo, vezino de esta dicha Ziudad, como hermano mayor de la dicha Hernadad de Nuestro Padre Jesús, y en nombre y en vos de los demás Hermanos y diputados de ella, por quienes prestó vos y cauzión de rato en sufiziente y bastante forma, y se obligó a que estará y pasará por todo quanto en dicho nombre hiziere y otorgare, y a manera de fianza y por corroborazión de la dicha cauzión, obligó los bienes y rentas de la dicha hermandad, havidos y por haver, otorgó que la azetaba y azetó en su favor, según y como en ella se contiene, y por su thenor se obligó a que cumpliéndose por el dicho Don Juan Francisco Parexa, vezino de la Ciudad de Andúxar, y Maestro de Ebanista en ella, con todo lo que es de su cargo, por esta escriptura, el otorgante, como tal hermano mayor de dicha Hermandad, y en su nombre, le dará quarto correspondiente para executar dicha obra, el carey y plata que nezesitare, y pagarles los hornales en la conformidad que ba expresssado en esta escriptura, por todo lo cual, cada cossa o parte de ello, se le a de poder a premiar y sin que fuese nezessario otro auto, prueva, ni sitazión alguna, aunque de derecho se requiera y todo lo cumplirá en esta Ziudad con las costas de su cobranza. 
Y ambos los dichos otorgantes, cada uno en lo por sí otorgado, prometieron y se obligaron de haver por firme esta escriptura, para cuya firmesa y cumplimiento obligaron el dicho Marqués de Alcántara, los bienes y rentas de dicha Hermandad, y el dicho Don Juan Francisco de Parexa, su persona y bienes y todos havidos y por haver, y dieron poder cumplido a las justizias y Juezes que de la causa puedan y devan conozer, y en espezial el dicho Don Juan, a las de esta Ziudad, a cuio fuero y jurisdizión se obligó y sometió, y renunció el que de presente tenía, y otro que nuevamente ganara y adquiriera y la Ley si combenerit omnium iudicium, y demás que devan renunziar los que se obligan a fuero estraño, para que no le balgan en juizio ni fuera de él, y a todas las dichas Justizias para que les obliguen a su entero cumplimiento y como si fuese por sentenzia pasada en authoridad de cosa jusgada, y renunziaron las leyes de su favor y la que prohibe su general renunziazión, y así lo otorgaron siendo presente por testigos el Doctor Don Salvador Silbestre Clavijo, Don Juan de Labrada, presbíteros, y Don Juan de Carrisosa, vezinos de esta dicha ciudad, y los otorgantes lo firmaron, a quienes yo el presente escrivano doi fee que conosco. El Marqués de Alcántara. Juan Francisco de Pareja. Sin derechos. Doy fee. Francisco Manuel Peláez escribano público". 


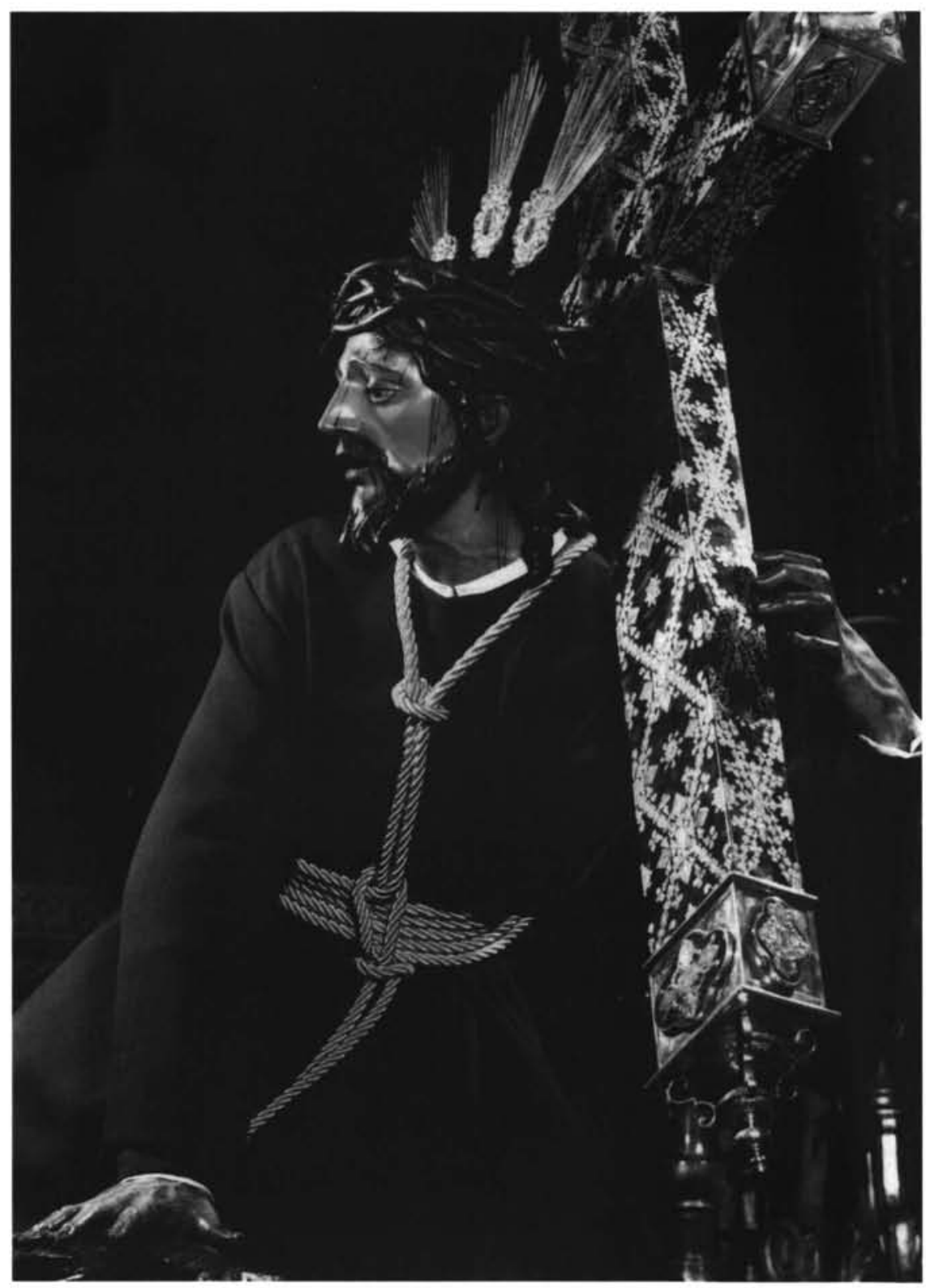

Lám. 1.

N.P. Jesús de las Penas. Iglesia de San Vicente Mártir. Sevilla. 


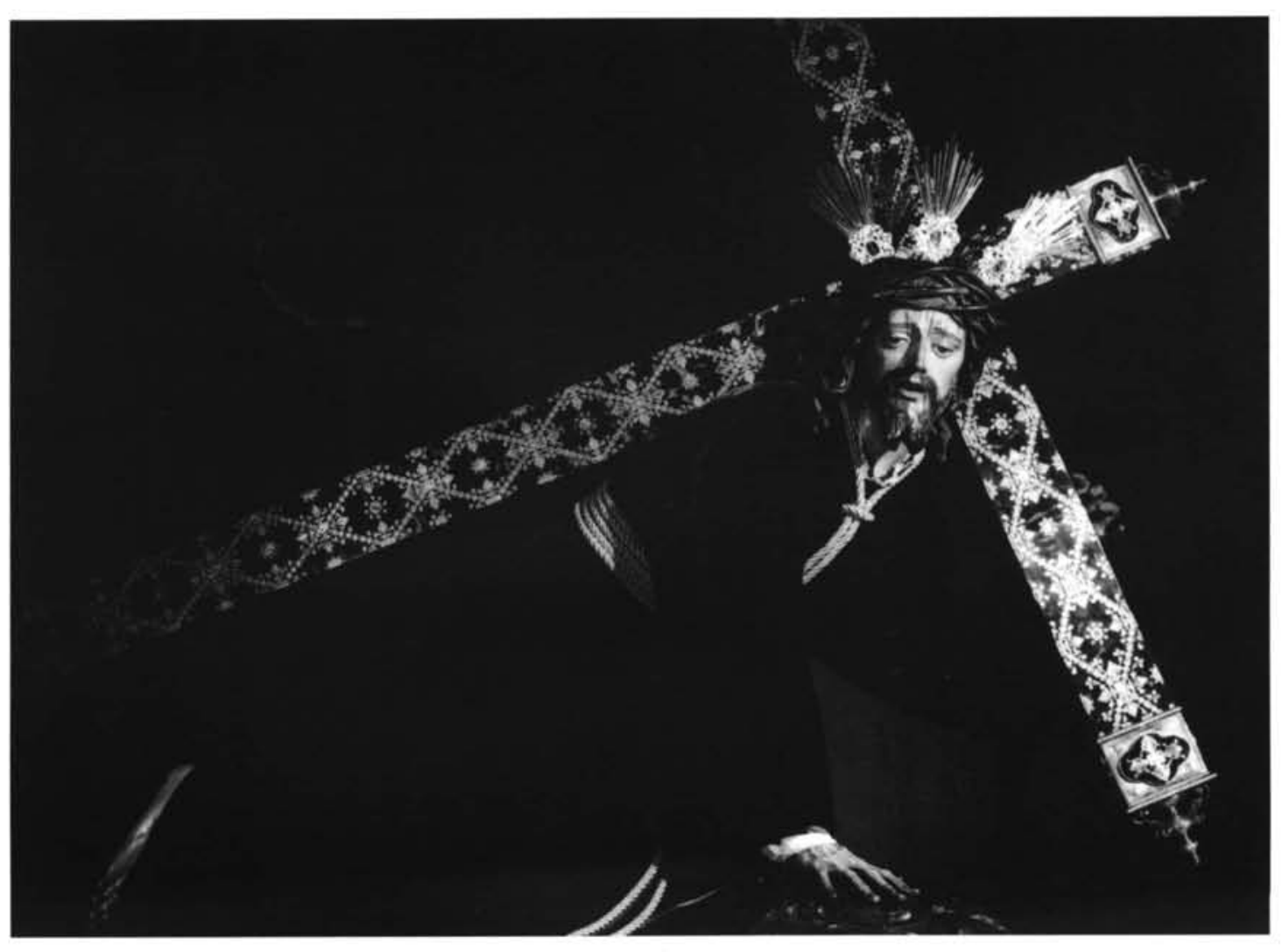




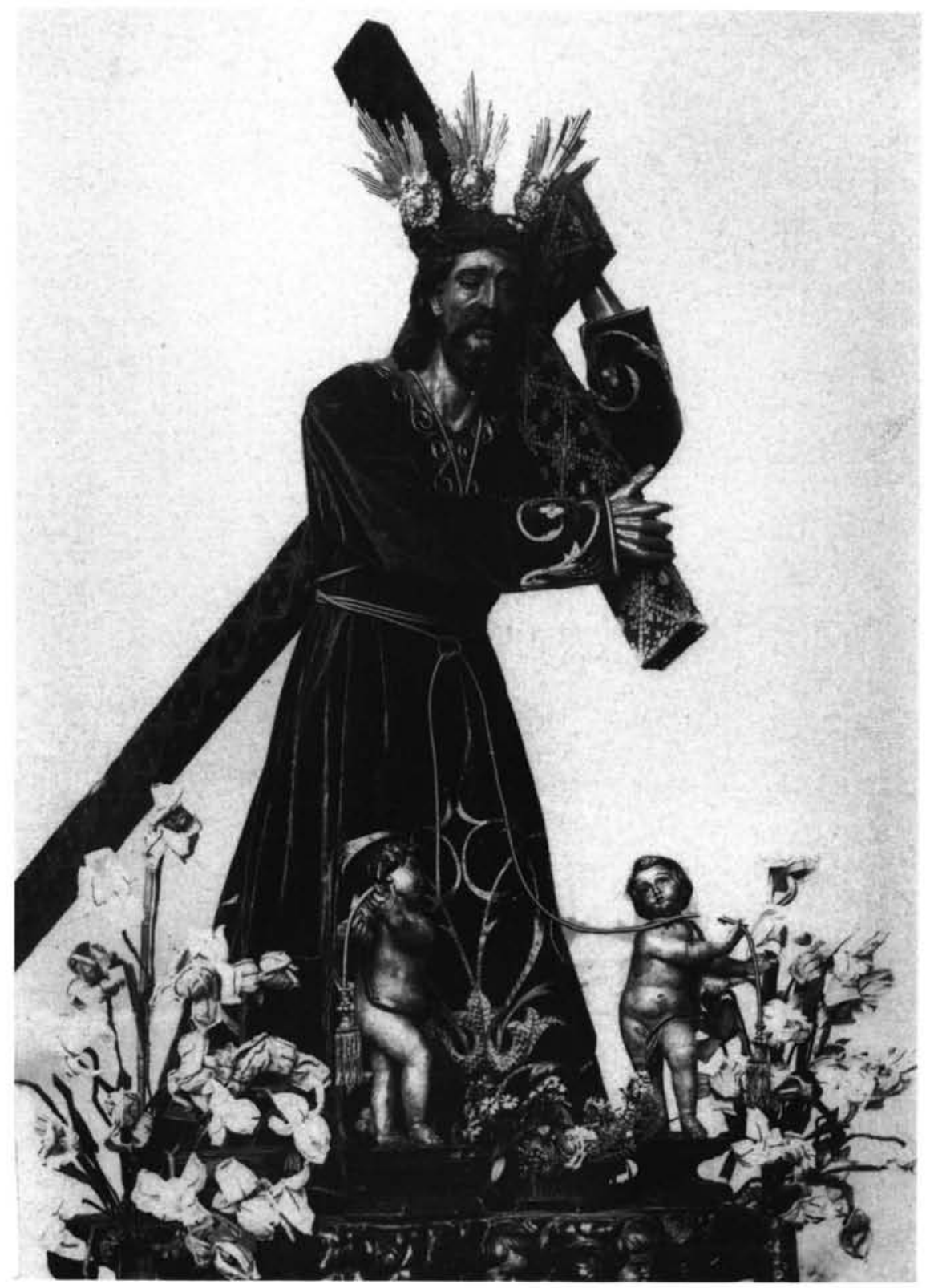

Lám. 3.

N.P. Jesús Nazareno. Iglesia de San Juan Bautista. Ecija. 


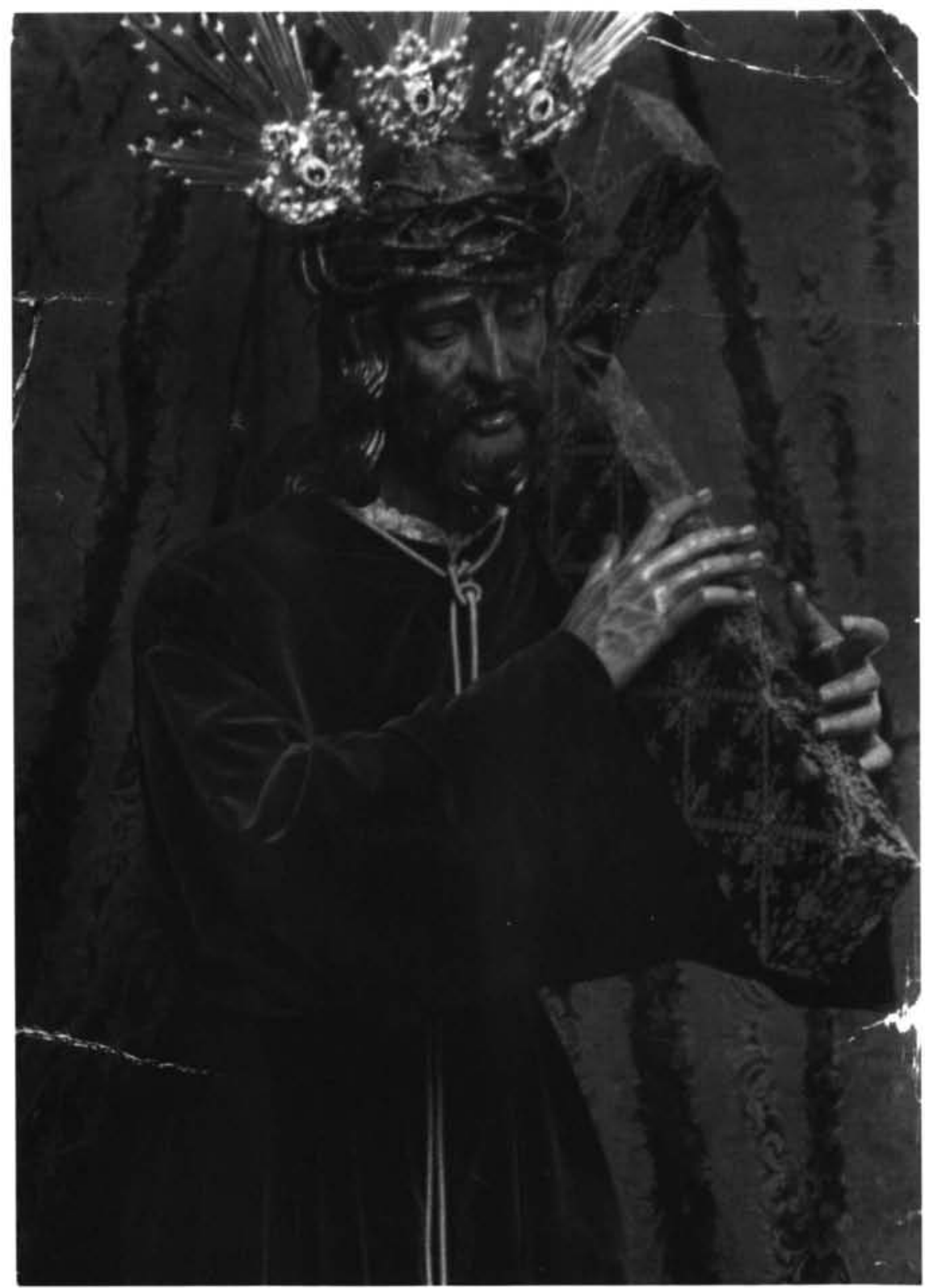

Lám. 4.

N.P. Jesús Nazareno. Iglesia de San Juan Bautista. Ecija. 


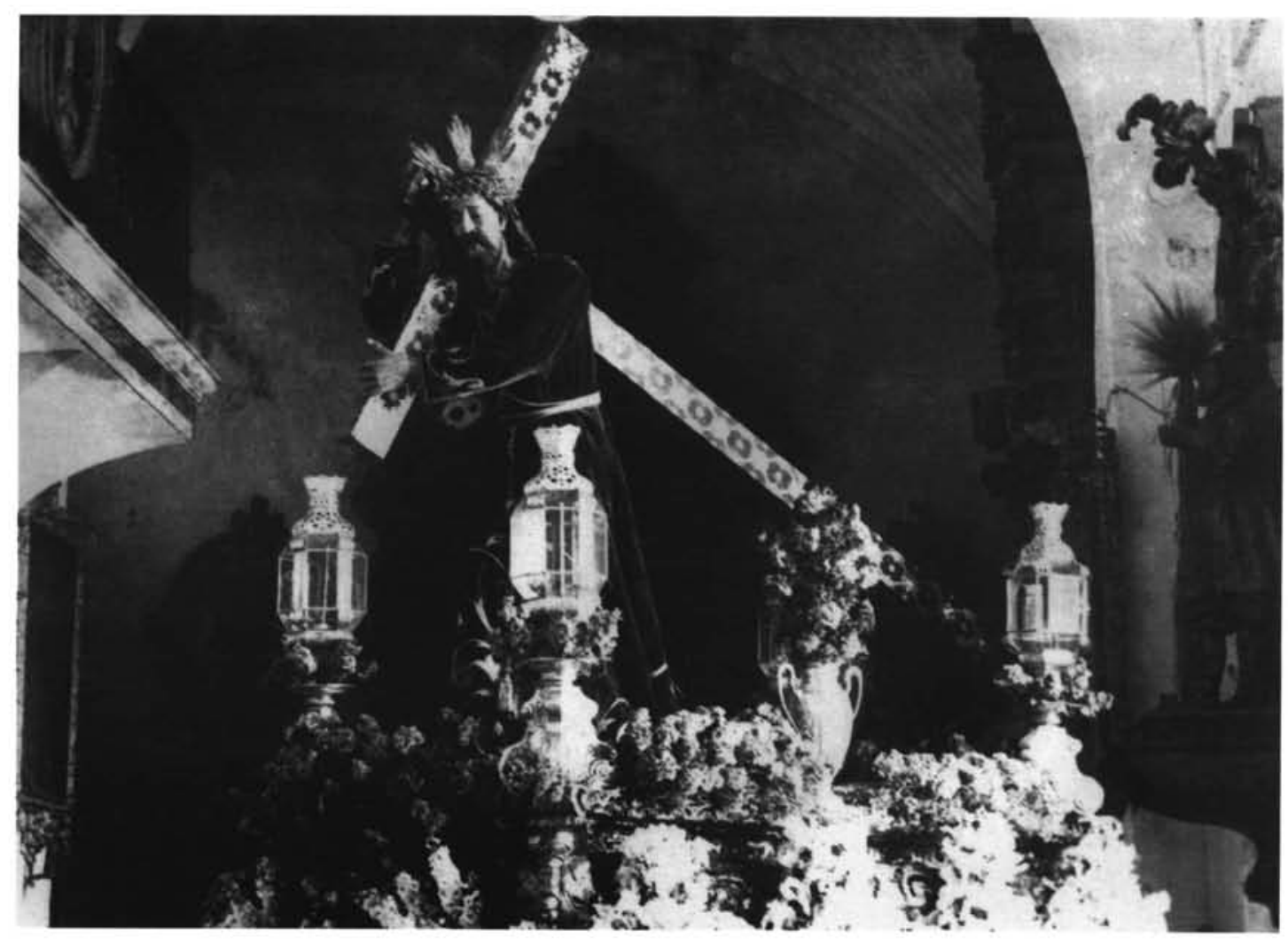

Lám. 5.

Retablo cerámico. 1962. Plazuela de San Juan. Ecija. 


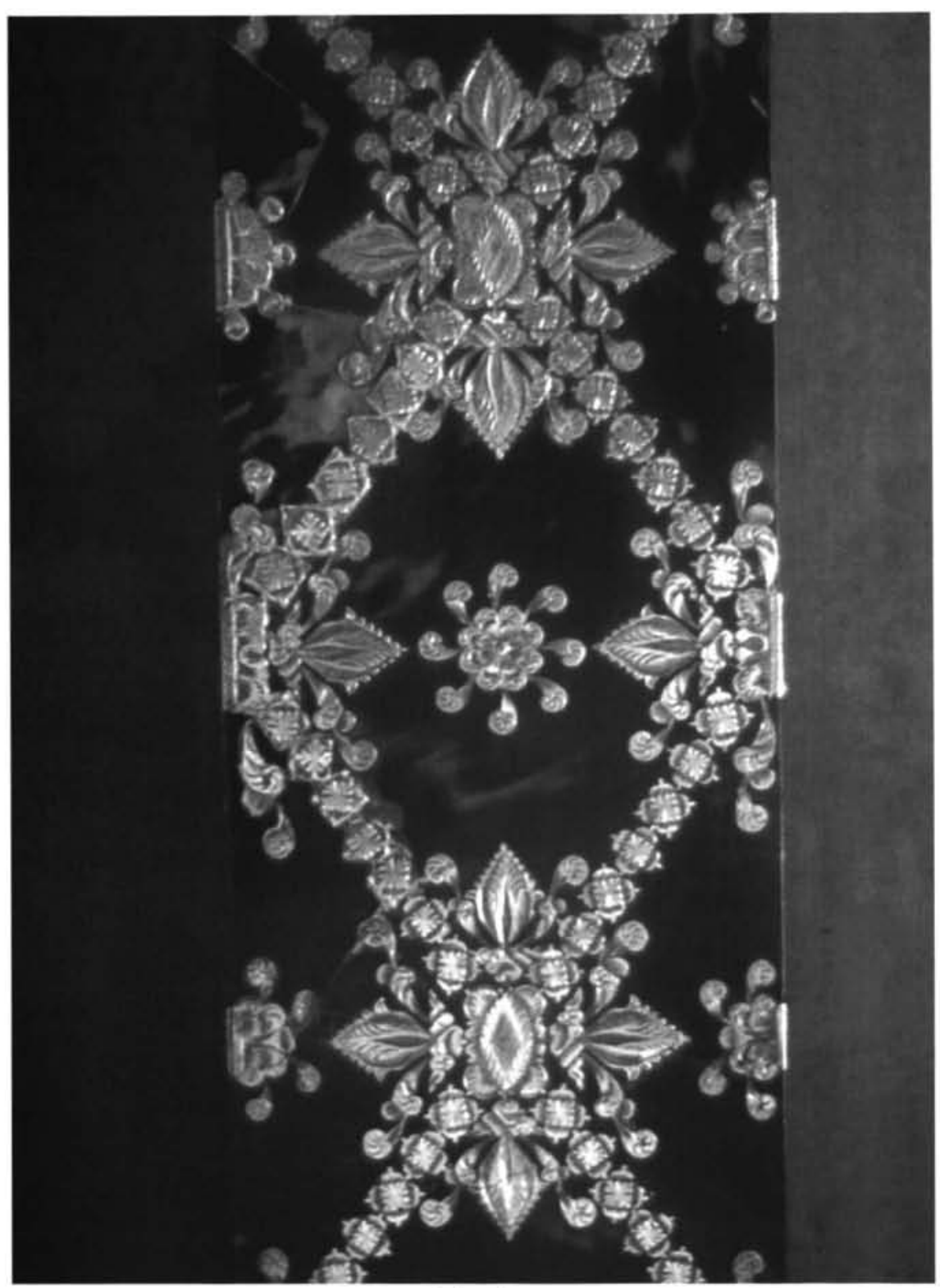

Lám. 6.

Juan Francisco de Pareja. Cruz de N.P. Jesús de las Penas. 1735 (Detalle). Iglesia de San Vicente Mártir. Sevilla. 